\title{
Historia Antigua e Historia de la relación entre Antigüedad Clásica e ideologías políticas: apuntes para una convivencia necesaria
}

\author{
Ancient History and History of Classical Antiquity and political \\ ideology: notes for a necessary coexistence
}

\author{
RicARdo del Molino García*
}

\begin{abstract}
RESUMEN
La presente comunicación pretende reflexionar acerca del lugar, la función y la necesidad de la Historia Antigua en la historia de la recepción y apropiación política de la Antigüedad, a partir de varios aspectos fundamentales de ésta y de una breve exposición de la investigación doctoral, realizada por el comunicante, titulada La Antigüedad Clásica en Nueva Granada, 1767-1816.

PALABRAS CLAVE:

Apropiación política de la Antigüedad, uso y abuso de la Antigüedad, tradición Clásica, estudios interdisciplinares, Nueva Granada.
\end{abstract}

ABSTRACT

This paper aims to reflect on the place, role and necessity of Ancient History in the History of the reception and political appropriation of Antiquity, starting from several key aspects of Antiquity itself and from a brief statement of the doctoral project conducted by the author, entitled Classical Antiquity in Nueva Granada, 1767-1816.

\section{KEYWORDS:}

Political appropriation of Antiquity, use and abuse of Antiquity, Classical tradition, interdisciplinary studies, Nueva Granada.

En las últimas décadas han proliferado las investigaciones acerca de la relevancia y el papel del mundo grecorromano como referente operativo y paradigma orientador de actores, sistemas e ideologías políticas. El interés por esta relación surgió a principios del siglo XX, cuando autores anglosajones analizaron la presencia e influencia del legado clásico en diferentes aspectos ideológicos del pro-

* Facultad Ciencias Sociales y Humanas, Universidad Externado de Colombia (Calle 12 n. ${ }^{\circ}$ 1-17 este. Bogotá. Colombia). E-mail: ricardodelmolino@gmail.com.

Artículo basado en la comunicación leída el 21 de Mayo de 2008, en la VII edición del Encuentro de Jóvenes Investigadores de Historia Antigua de la Universidad Complutense de Madrid. 
ceso de independencia de los EE.UU. A continuación, la atención se amplió a otros momentos históricos, destacando la Revolución Francesa (Del Molino 2007: 7685). En un principio, la mayoría de las investigaciones, ligadas a la Filología clásica, se desarrolló dentro del marco disciplinar de la 'tradición clásica'; sin embargo, paulatinamente se fue abriendo a otras áreas de conocimiento hasta llegar a conformar una sensibilidad historiográfica, cuyo denominador común es el estudio del 'uso y abuso' político del pretérito grecolatino', que algunos autores incluyen en los estudios sobre el uso público de la Historia?

En la actualidad, el heterogéneo e interdisciplinar conjunto de publicaciones sobre la relación entre Antigüedad clásica y la política constituyen un corpus teórico de tal alcance que, de ser sistematizado, podría conformar la 'Historia de la relación entre Antigüedad Clásica e ideologías políticas' o 'Historia de la interrelación entre la ideología dominante y la cultura clásica' que L. Canfora propone (1991). No obstante, existen pocos trabajos que intenten hilar una Historia general de la recepción y apropiación política de la Antigüedad, de los cuales, además del mencionado libro de Canfora, cabe citar la obra de A. Ginzo, donde se muestra un recorrido por las «confrontaciones con la Antigüedad clásica que jalonan la Historia de la cultura occidental» (Ginzo 2002: 133).

La presente comunicación pretende reflexionar acerca del lugar, la función y la necesidad de la Historia Antigua en esta 'Historia de la recepción y apropiación política de la Antigüedad', a partir de varios aspectos fundamentales de ésta y a través de un caso particular de investigación doctoral titulada La Antigüedad Clásica en Nueva Granada, 1767-1816: Recepción y apropiación política de la Antigüedad grecorromana en el Tránsito del Antiguo Régimen a la Modernidad en Colombia.

En primer lugar, se someterá a discusión la noción historiográfica y cultural de 'Antigüedad', que sirvió de punto de partida de la investigación doctoral citada. Seguidamente, se mostrará la recepción y apropiación política del pretérito grecolatino como objeto de estudio de las Ciencias de la Antigüedad, a partir de la locución «actualización del pasado» propuesta por Fernando Gascó, como acto per se necesario para el establecimiento de un vínculo o relación entre el pretérito y el presente. En tercer lugar, se formulará una propuesta personal metodológica de apertura a la interdisciplinariedad que posibilite la aprehensión, en su totalidad, del complejo fenómeno de la apropiación política de la Antigüedad Clásica. Finalmente, se expondrá, muy brevemente, la investigación doctoral realizada bajo el marco teórico y metodología señalados.

1 Desde que en 1975 M. I. Finley utilizó la alocución 'uso y abuso del pasado', ésta se ha convertido en una convención muy empleada por parte de la historiografía contemporánea, por ejemplo utilizada por Gascó y Falque (1992), Wyke y Biddiss (1999).

2 G. Pasamar explica que el concepto de 'uso público de la Historia' es una denominación, reconocida por Jürgen Habermas, acuñada en el fragor de la Historikerstreit de los historiadores alemanes en 1986 «para referirse explícitamente a un tema tradicional y tan antiguo como el propio conocimiento histórico: el de las funciones políticas y culturales inherentes a las representaciones del pasado, inseparables de sus circunstancias políticas y sociales» (Pasamar 2004: 15). Para el origen y definición de uso público de la historia, la formulación de Jürgen Habermas y su aplicación a la Historikerstreit alemana, puede acudirse a Hartog y Revel (2001: 7-74). 


\section{EL PUNTO DE PARTIDA: ANTIGÜEDAD COMO NOCIÓN HISTORIOGRÁFICA Y CULTURAL}

'Antigüedad clásica' es una noción historiográfica, en tanto que su contenido está delimitado por un arco temporal establecido convencionalmente por la disciplina de la Historia Antigua (Plácido 1995: 140), y cultural, puesto que es el producto de una determinada sociedad, específicamente la europea ${ }^{3}$, que engloba espacios, sociedades e individuos, así como sus producciones intelectuales y materiales, ubicados convencionalmente dentro de los límites temporales que la disciplina de la Historia otorga a las antiguas Grecia y Roma. Este concepto adquiere un significado propio y, en ocasiones, una naturaleza paradigmática referencial como consecuencia de la recepción y el uso particular que de él se hace en cada momento y en cada ámbito específico.

Lo cierto es que, desde el Renacimiento, las diferentes comunidades y personajes relevantes de la cultura occidental han representado e imaginado de modo muy variado la 'Antigüedad clásica', bien por el mayor o menor conocimiento histórico del referente real, bien por la participación de la memoria colectiva o la imaginación, bien por la sumisión a las circunstancias y objetivos perseguidos en cada momento. En consecuencia, la noción de 'Antigüedad clásica' ha adquirido diferentes significados en cada individuo o comunidad donde se ha recibido y utilizado, con sus consecuentes imágenes y representaciones.

Tradicionalmente, las prefiguraciones del pasado grecorromano surgidas en diferentes individuos o sociedades, y en momentos diversos, muchas veces ajenas a los referentes históricos en los que se basan o reproducen, eran consideradas un producto cultural de épocas impropias a las antiguas Grecia y Roma, por lo que quedaban excluidas de los estudios sobre la tradición clásica. Sin embargo, en la actualidad es lícito expresar una 'reivindicación radical', consistente en defender que el estudio interdisciplinar de estas prefiguraciones debe enmarcarse en el escenario de la Historia Antigua, pues ésta se modifica en cada período por la intervención que en ella realiza cada presente.

\section{LA RECEPCIÓN Y APROPIACIÓN POLÍTICA DEL PRETÉRITO GRECOLATINO COMO OBJETO DE ESTUDIO DE LAS CIENCIAS DE LA ANTIGÜEDAD}

Lo que realmente interesa como premisa fundamental de esta 'reivindicación radical' es advertir que tanto la Historia, como proceso empírico cognitivo (Lowenthal 1998), como las representaciones de la Antigüedad clásica permiten la ac-

${ }^{3}$ Las convenciones historiográficas no sólo responden a motivaciones científicas o epistemológicas, también están sometidas a los intereses políticos, económicos, sociales o culturales del momento en el que se crean, se usan o se mantienen. El eurocentrismo del concepto le viene dado por la propia génesis del concepto 'Antigüedad clásica' surgido en el Humanismo renacentista y porque «son criterios propios del mundo mediterráneo septentrional los que en última instancia lo definen» (Plácido 1995: 140). 
tualización del Pasado, acto per se necesario para el establecimiento de un vínculo o relación entre el pretérito y el presente. Pues, como indicaba F. Gascó, el pasado se actualiza, es decir, «se hace presente en el presente», de dos formas posibles 4 : la primera, por sí mismo, en tanto que perduran en el acontecer histórico sus huellas. Es decir: los restos o 'reliquias' del pasado se mantienen en el presente y son percibidos, procesados, conceptualizados y transferidos por las ideologías, sujetos y sociedades de cada momento ${ }^{5}$. Esta forma de actualización del Pretérito coincide con lo que J. Assmann propone cuando dice que «el presente es visitado por el pasado y éste es moldeado, inventado, reinventado y reconstruido por el presente» una vez que lo recepciona (2003: 22). Por otro lado, la segunda forma de actualización del pasado implica una voluntad presente de recuperación, es decir, el pretérito se actualiza en el momento en el que una ideología, un sujeto o una comunidad buscan en él un beneficio actual para su legitimación o para cumplir objetivos determinados en ese presente. Esta segunda modalidad coincide con lo que J. H. Plumb denominó «pasado frente a Historia» (1974), aceptada por autores como A. García Calvo (1983) o el propio F. Gascó (1991: 71-84).

Plumb hace una distinción precisa entre pasado e Historia para referirse a dos modos o formas de mirar, de acercarse al pretérito. Para este autor, el pasado sería una «generalización estructural que usaban nuestros mayores pera esclarecer el sentido de la vida por medio de la historia» (Plumb 1974: 13). Por tanto, el pasado es la visión de lo acontecido en virtud de una funcionalidad presente, una ideología imbuida de finalidad o, enunciado en la propias palabras de Plumb, «es siempre una ideología forjada con un fin preciso para dominar a otros hombres, para orientar la evolución de una sociedad o para inspirar una clase». Frente a esta idea, Plumb propone que el pasado no es nunca la Historia, por más que algunos de sus elementos puedan ser históricos, ya que para él «la Historia es un quehacer intelectual, es ciencia» (1974: 114). Esta diferenciación entre pasado e Historia coincide con otras formulaciones como la dada por M. I. Finley, que distingue entre el estudio sistemático de la Historia y aquello que no lo es y sirve para diferentes objetivos (1984: 12, 29), o la propuesta de J. Assmann que diferencia entre Historia y Mnemohistoira o Historia del recuerdo (2003: 26).

Por tanto, del mismo modo que F. Gascó reflexionaba sobre el pretérito en general y su relación con el presente, los referentes históricos - Historia- y las representaciones - pasado- contenidos en el concepto de 'Antigüedad clásica' se actualizan en cada presente, bien por sí solos o por medio de una voluntad mediadora. Una vez definidos los dos posibles modos de relación entre el presente y

${ }^{4}$ Fernando Gascó definió la expresión ‘actualidad del pasado' como «la locución que utilizamos para indicar que algo ya acaecido, que fue o que tuvo su floruit tiempo atrás, mantiene una influencia más allá de lo que pudiéramos llamar su 'ciclo de vida natural'. Este enunciado está compuesto por dos fundamentos concurrentes aunque de distinta naturaleza. Por un lado, aquel por el que todo lo acaecido tiempo atrás se hace de una u otra forma efectivo en nuestro presente, sin mediar la intencionalidad o voluntad de nadie, y por otro lado, aquel fundamento por el que una sociedad determinada en un período concreto y por distintas circunstancias recupera de una u otra manera una parte de su pasado en el que desea reconocerse, encontrar su identidad o con el que desea 'renacer' o renovarse» (Gascó 1993: 9-10).

5 'Reliquia' como resto material tangible del pasado (Lowenthal 1998). 
Historia Antigua e Historia de la relación entre Antigüedad Clásica e ideologías políticas...

la Antigüedad clásica es importante diferenciar el ámbito en el que ésta se produce. Es decir, la Antigüedad grecorromana tendrá unas características y unas particularidades diferentes dependiendo del ámbito en el que se recibe y en el que se usa. Será distinta, por ejemplo, la relación establecida en la esfera artística de la de la política. No obstante, como se ha advertido, la presente comunicación sólo tratará de la recepción y apropiación política.

\section{EL ESTUDIO DE LA RECEPCIÓN Y APROPIACIÓN POLÍTICA DE LA ANTIGÜEDAD CLÁSICA}

Cabe ocuparse de varios aspectos epistemológicos acerca de la apropiación política de la Antigüedad clásica relativos a quién debe estudiar tal fenómeno, de qué modo, y cuál es el aporte de este tipo de investigaciones a la ciencia y a la sociedad actual. Sobre la última cuestión, qué aporta el estudio de la recepción y apropiación política de la Antigüedad clásica al conocimiento histórico y qué utilidad social puede llegar a tener, cabe argumentar que cada representación, prefiguración o conceptualización de la Antigüedad, así como cada 'uso y abuso', emanan de un momento histórico, de unos sujetos y unas ideologías determinadas, y en consecuencia si se conoce la interpretación que éstos hacen de aquella podrá aclararse aspectos de ellos mismos. Como afirma D. Plácido, "cada imagen del mundo clásico es un fenómeno histórico nuevo que sirve para comprender la época de los imitadores» (1992: 12). A este respecto, y en particular, no ha de olvidarse que en el ámbito político, al menos hasta el tránsito a la Modernidad, la Antigüedad clásica fue para todas las ideologías políticas una 'noción-eje'6, un locus communis político, en tanto que en ella se localiza el origen de la ciencia política. Por tanto, y parafraseando a C. Edwards, no queda duda de que la Antigüedad clásica es un fértil paradigma especular e ideal en el landscape simbólico político occidental que debe ser estudiado para comprender en su totalidad aquellas sociedades donde habita (Edwards 1999: XI).

A propósito de quién y cómo se debe estudiar el fenómeno de la recepción y apropiación política de la Antigüedad clásica, cabe acudir a la amplia gama de posibilidades epistemológicas y metodologías surgidas desde principios del siglo XX para darse cuenta de que el estudio de éste fenómeno se encuentra en los ámbitos de la inter- y la trans-disciplinariedad, siempre aplicadas a las Ciencias de la Antigüedad. Los primeros estudios acerca de la recepción y apropiación política de la Antigüedad clásica quedaron dentro de la disciplina de la tradición clásica. Sin embargo, esta disciplina abordaba el tema desde el convencimiento de la existencia de un legado clásico inmutable que nunca había roto su cordón umbilical con aquel tiempo que le vio nacer. Es decir, el estudio se hacía sólo desde el pla-

${ }^{6}$ Respecto al concepto de 'noción-eje', J. C. Rodríguez afirma que «cada matriz ideológica se enuncia a través de unas nociones-eje a las que otorga el carácter de elementos esenciales e inalterables de la realidad, para inmediatamente borrarse a sí misma en tanto que tal, amparándose y escondiéndose detrás de esas nociones a las que ya ha conseguido establecer como la verdad misma de la vida» (1974: 13). 
no de la recepción hasta el punto en que la tradición clásica se vinculó con la llamada historia de la recepción, e incluso los términos se hicieron intercambiables (Hampe 1999: 7). Por tanto, no era objeto de interés de esta disciplina todas aquellas representaciones o prefiguraciones que no tuvieran un ancla tangible en las antiguas Grecia y Roma. Sin embargo, a partir de la mitad del siglo XX, el horizonte epistemológico se amplió y se comenzó a admitir el estudio desde cualquier área en la que se produce la apropiación; es decir, desde la política, la sociología, la iconografía, desde las diferentes especialidades de la Historia —en tanto que la apropiación es un acontecer concreto bien medieval, moderno o contemporáneo-, desde el objeto apropiado y su alteración de las reliquias — si son fuentes textuales cabe desde la Filología, pero si lo alterado son restos tangibles, el estudio sería posible desde la Arqueología-, desde el análisis de la propia acción de apropiar -antropólogos, psicólogos sociales, sociólogos-, etc. Y por supuesto, el estudio de la relación entre Antigüedad clásica y Política se amplió a la Historia conceptual y a la Historia cultural de las representaciones de la Antigüedad, mnemohistoria o Historia del recuerdo (Assmann, 2003). Lo cierto es que la Historia semántica o conceptual es pertinente en este tipo de estudios en tanto que la Antigüedad clásica es una de esas «nociones a través de las cuales se estructura el mundo» - al menos desde el Renacimiento hasta mitad del siglo XIX—, que «no son las mismas que las de nuestros antepasados», ya que «las representaciones retrospectivas de esos mundos pretéritos están decisivamente influidos por los filtros categoriales" de cada momento (Fernández y Fuentes 2004: 13). Luego debe estudiarse no sólo la Antigüedad clásica como noción que estructura el mundo, sino también sus filtros. Y aún más, acudiendo a Koselleck, no debe olvidarse el estudio de la 'estructura temporal interna' de la noción de Antigüedad clásica, pues ésta está compuesta por diferentes niveles de profundidad histórica y en cada nivel existen diferentes o superpuestas representaciones (Koselleck 2004: 36-37).

En conclusión, la interdisciplinariedad admite incluir en los estudios de la recepción y apropiación política de la Antigüedad clásica el análisis de las representaciones, imágenes e incluso recuerdos del pretérito griego y romano, aún siendo absolutamente independientes de sus referentes históricos, ya que permite el acercamiento al objeto desde ámbitos y áreas antes vetados en la disciplina de la tradición clásica.

\section{BREVE EXPOSICIÓN DE LA TESIS DOCTORAL «LA ANTIGÜEDAD CLÁSICA EN NUEVA GRANADA, 1767-1816»}

Al acudir al contenido del corpus teórico de la sensibilidad trans-disciplinar del estudio de la recepción y apropiación política de la Antigüedad clásica, se percibe que esta 'Historia de la relación entre la Antigüedad clásica e ideologías políticas' recorre todos los períodos de la historia de Occidente, por lo que cabe decir con Plácido que «en cierto modo, la historia de la humanidad (Occidental) es la de las relaciones de cada sociedad con el modelo clásico» (Plácido 1992: 12). Sin embargo, si se presta atención a los objetos de estudio particulares de los trabajos e investiga- 
ciones, se advierte que existe una privilegiada atención sobre la recepción y apropiación de la Antigüedad grecorromana en dos momentos muy específicos de la historia occidental, la Independencia de los EE.UU. y la Revolución Francesa ${ }^{7}$. Para la historiografía actual, éstos son los dos momentos de mayor relación entre la Antigüedad clásica y las ideologías políticas. No en vano, según la perspectiva de Canfora, los procesos de emancipación estadounidense y revolucionario francés, además de marcar el final del Antiguo Régimen y el inicio de la Modernidad ${ }^{8}$, serían los últimos acontecimientos en los que los referentes y el lenguaje político se mantienen clásicos (Canfora 1991: 23; 2004: 63).

Efectivamente existió una correspondencia entre la recepción y apropiación política de la Antigüedad clásica y el Tránsito del Antiguo Régimen a la Modernidad en los Estados Unidos y en Francia. Por tanto, es legítimo preguntarse si también existió esa relación en otros procesos similares localizados en Iberoamérica ${ }^{9}$. Sin embargo, no existe ninguna corriente historiográfica consolidada que se ocupe de ello. ¿Cabe entonces afirmar, a partir de la ausencia de estudios, que no hubo ninguna relación entre la Antigüedad clásica y la ideología en los procesos de emancipación y revolución hispanoamericanos? La respuesta es sencilla. Si se consulta cualquier compilación documental del pensamiento emancipador hispanoamericano, se comprueba que las alusiones, menciones y referentes grecorromanos están presentes en un número muy considerable en los discursos, proclamas, exhortaciones y actas oficiales. Por tanto, si ciertamente la Antigüedad clásica estuvo presente en los procesos de emancipación de los territorios de la Corona Española en América, ¿cómo debe valorarse la ausencia de estudios similares a los realizados por la historiografía sobre la recepción y apropiación política de la Antigüedad clásica en los Estados Unidos y en Francia, durante el mismo momento histórico?

Ante este vacío historiográfico, la tesis doctoral realizada por el comunicante pretende poner de relieve la existencia de la relación entre política y Antigüedad grecolatina en al menos uno de los territorios de la Monarquía hispánica durante su proceso emancipador, y con ello se propone advertir que el estudio de la recepción y la apropiación política de referentes antiguos en los procesos de emancipación hispanoamericanos debe ser reconocido, impulsado y convertido en un verdadero objeto de estudio por aquella sensibilidad historiográfica que lenta y asistemáticamente está construyendo una 'Historia de la recepción y apropiación política de la Antigüedad clásica'.

El trabajo realizado, resultado de una investigación de cuatro años realizada en España y Colombia en torno a la presencia del legado político clásico en este país andino, se enmarca en un doctorado en Humanidades dentro de la disciplina de la

7 Sistematizado en Del Molino (2007).

8 'Modernidad' en sentido político, y no como periodización histórica.

9 Franceses y estadounidenses no fueron los únicos protagonistas del proceso de tránsito del Antiguo Régimen a la Modernidad. En la actualidad, a pesar de las voces que niegan el carácter revolucionario de los procesos emancipadores hispanoamericanos, una buena parte de la historiografía contempla que éstos sí son parte integrante de tal proceso histórico. 
Historia Antigua. A este respecto creo necesario explicitar el convencimiento personal, como licenciado y doctor en Humanidades, en la necesidad y utilidad de una formación como experto en la inter y en la trans-disciplinariedad, pero siempre aplicadas a una disciplina, en este caso a la Historia Antigua. Defiendo que la investigación realizada es Historia Antigua desde el momento en el que el objeto de estudio es la Antigüedad, definida como noción historiográfica y cultural, como se ha mostrado anteriormente, y en tanto que la representación empírica o imaginaria del pasado clásico que confeccionaron los intelectuales neogranadinos analizados es una formalización de la Antigüedad que determina de cierta manera la propia Historia Antigua al menos como se concibe en América.

Por ende, desde mi aportación como experto en la inter-disciplinariedad dentro de la Historia Antigua, expreso mi deseo de poder contribuir con la tesis realizada a la consolidación de la sensibilidad historiográfica, que estudia la 'Historia de la recepción y apropiación política de la Antigüedad clásica', línea que ha sido desarrollada en España por historiadores de la Antigüedad, como Domingo Plácido, Fernando Gascó, Fernando Wulf, José Beltrán, Pedro Barceló, Francisco Javier Gómez Espelosín, Clelia Martínez Maza, o Mirella Romero.

El punto de partida de la investigación doctoral fue el propio corpus teórico y asistemático de esta 'Historia de la recepción y apropiación política de la Antigüedad clásica'. En él se observa la evidente primacía de estudios acerca del influjo, presencia y uso de la Antigüedad clásica en los dos procesos históricos paradigmáticos de tránsito del Antiguo Régimen a la Modernidad ${ }^{10}$, es decir, en la Independencia de los EE.UU. y la Revolución Francesa ${ }^{11}$. Por tanto, si estas dos dinámicas son los paradigmas de un ciclo histórico mayor occidental, que algunos denominan 'Revoluciones Atlánticas burguesas', en el que están incluidos los procesos revolucionarios e independentistas acontecidos en la América, creo que es legítimo preguntarse si en éstos también se dio una apropiación política del pretérito clásico. Lo cierto es que basta consultar cualquier compilación de pensamiento político iberoamericano emancipador para confirmar que la Antigüedad no por ignorada es menos existente en aquellas dinámicas de construcción nacional republicana acaecidas en Hispanoamérica.

El trabajo de investigación consistió, fundamentalmente, en localizar, sistematizar y analizar las menciones, alusiones y referencias al pretérito grecorromano presentes en el imaginario y en el pensamiento formal, así como en la práctica política, en Nueva Granada durante la fase previa a la emancipación (1767-1810) y en la Primera República o Patria Boba (1810 a 1816). Los resultados obtenidos permiten afirmar, como conclusión general, que la Antigüedad clásica estuvo presente en el proceso de emancipación colombiano, al menos en su primera fase (1810-1815/16), no por imitación del uso que estadounidenses y franceses hicieron en sus correspondientes procesos de tránsito del orden monárquico al sistema re-

10 De nuevo, 'Modernidad' en sentido político, y no como periodización histórica.

11 La bibliografía acerca de la presencia de la Antigüedad en la independencia estadounidense y en la revolución francesa es abundante. Puede consultarse en Del Molino (2007). 
Historia Antigua e Historia de la relación entre Antigüedad Clásica e ideologías políticas...

publicano, sino porque había sido transferida previamente en el Virreinato y acogida como propia por la elite ilustrada dirigente que lideró después la Primera República. Por tanto, se concluye que la Antigüedad grecorromana presente en el pensamiento formal de la Patria Boba legitimó tanto posturas teóricas como prácticas y comportamientos políticos de los próceres neogranadinos de la Generación de 1810.

\section{BIBLIOGRAFÍA}

ASSMANN, J. (2003), Moisés el Egipcio, Madrid.

CANFORA, L. (1991), Ideologías de los Estudios Clásicos, Madrid.

- (2004), La Democracia. Historia de una Ideología, Barcelona.

DEL MOLINO, R. (2007), «La apropiación política de la Antigüedad grecorromana: de la tradición clásica a la interdisciplinariedad", Revista de Historiografía 5.3, 76-85.

EDWARDS, C. (1999), Roman Presences. Receptions of Rome in European Culture, 17891945, Cambridge.

FERNÁNDEZ SEBASTIÁN, J. y FUENTES, F. J. (2004), «A manera de introducción. Historia, lenguaje y política», Ayer 53, 11-26.

FINLEY, M. I. (1984), Uso y Abuso de la Historia, Barcelona.

GARCÍA CALVO, A. (1983), Historia contra Tradición. Tradición contra Historia, Madrid,

GASCÓ, F. (1991), «Reinventado Atenas», Revista de Occidente 118, 71-84.

- (1993), «Historiadores, falsarios y estudiosos de las antigüedades andaluzas», en Beltrán, J. y Gascó, F., eds., La Antigüedad como Argumento. Historiografía de Arqueología e Historia Antigua en Andalucía, Sevilla, 9-28.

GASCÓ, F. y FALQUE, E. eds. (1992), El Pasado Renacido. Uso y Abuso de la Tradición Clásica, Sevilla.

GINZO, A. (2002), El Legado Clásico. En Torno al Pensamiento Moderno y la Antigüedad Clásica, Alcalá de Henares.

HAMPE, T. comp. (1999), La Tradición Clásica en el Perú Virreinal, Lima.

HARTOG, F. y REVEL, J. dirs. (2001), Les Usages Politiques du Passé, París.

KOSELLECK, R. (2004), «Historia de los conceptos y conceptos de historia», Ayer 53, 27-45.

LOWENTHAL, D. (1998), El Pasado Es un País Extraño, Madrid.

PASAMAR, G. (2004), «El uso público de la historia, un dominio entre la urgencia y el desconcierto", en Forcadell, C. ed., Usos de la Historia y Políticas de la Memoria, Zaragoza, 15-32.

PLÁCIDO, D. (1992) «La recuperación del pasado en la Atenas del siglo IV a.C.», en Gascó, F. y Falqué, E. eds., El Pasado Renacido. Uso y Abuso de la Tradición Clásica, Sevilla, 173-185.

- (1995), Introducción al Mundo Antiguo: Problemas Teóricos y Metodológicos, Madrid.

PLUMB, J. H. (1974), La Muerte del Pasado, Barcelona

RODRíGUEZ, J. C. (1974), Teoría e Historia de la Producción Ideológica. Las Primeras Literaturas Burguesas, Madrid.

WYKE, M. y BIDDISS, M. D. eds. (1999), The Uses and Abuses of Antiquity, Berna. 